\title{
Analysis on Classroom Management of the Teaching of Chinese as a Foreign Language
}

\author{
Aijun $\mathrm{Wu}$ \\ Heihe University 164300 \\ Heihe, China
}

\begin{abstract}
As a foreign language, Chinese is new to foreign students. Besides, Chinese music, films and television dramas as well as animations are introduced to various countries in recent years, all of these attract people's attention to TCSL teachers. How to make Chinese teaching relaxed and enjoyable for foreigners while learning it well depends on teachers' methods of teaching and classroom management. Good classroom teaching effects not only rely on teachers' teaching ability, but also their classroom management capability.
\end{abstract}

Keywords-teaching of Chinese as a foreign language; classroom management; characteristics and problems

\section{INTRODUCTION}

Chinese for foreigners is becoming increasingly popular in recent years. With Chinese status enhancing year by year, the number of international students in China is constantly increasing, while more and more problems arise in the classroom teaching of Chinese as a foreign language. It is necessary to analyze and summarize teaching management of Chinese class as well as form some effective measures to achieve win-win both for teachers and students, especially international students' learning. How to deal with the relationship between teachers and students in Chinese classroom teaching for foreigners exert a tremendous influence on the smooth process of classroom teaching and the successful completion of teaching tasks. We not only advocate that teaching model focuses on students and that teachers play a leading role in teaching activities, but that the classroom teaching base on students' autonomic learning. However, in such a teaching model, what we should think twice are that how do teachers organize and manage the classroom teaching, and how do they guide students to finish learning tasks and develop good learning habits.

\section{DIFFERENT METHODS FOR DIFFERENT OBJECTS}

Teachers should make clear the teaching objects and goals before teaching and adopt different teaching methods for students of different levels. In primary teaching, teachers should focus on students and pay attention to practices in their teaching as well as taking different approaches. Besides, teachers should speak Chinese as much as possible and regard listening, speaking, reading, and writing as equally important. In intermediate teaching, teachers should pay attention to not only the teaching of pragmatic rules, phrases and articles, but the exercises of both reading and writing and increase the teaching of language culture properly in the meanwhile. In advanced teaching, teachers should focus on the practices of language skills and strengthen the teaching of communicative culture and the practices of phrases and articles. In class teaching, teachers should stimulate students' motivation to learn new knowledge by using students' enthusiasms on the new school and Chinese learning to help them realize the importance of learning Chinese well and stimulate their curiosity. In the 5 minutes before class, teachers should speak some common oral expressions or words for students learning and using. The teaching mode focusing on students stimulates students' learning initiatives and enthusiasms, which is through teachers'good classroom organization and guidance rather than loosing the management of students or making the class teaching disorder. In the organization of class teaching, teachers should get students truly involved in and eliminate the tension of students to get them participate in class activities, discussions and exchanges with others actively. What's more, teachers should be capable of maintaining classroom orders, prevent wasting time and offer necessary explanation and guidance to students, and help them complete Chinese learning and communicative tasks assigned by their teacher.

\section{To ELIMINATE THE TENSIONS OF STUDENTS}

Inevitably, foreign students will be nervous, anxious, and afraid of difficulties at the beginning of learning Chinese, such as being afraid to speak in front of other students, not willing to participate in class activities actively when their teacher assigns communicative tasks in class, being nervous and shy in oral expression and so on; teachers will often encounter these phenomena in the primary stage of teaching, and they should create a relaxing and lively atmosphere in class, making students participate in classroom activities freely. They should avoid casting irony and sarcasm on any students but encourage them more, also a joke occasionally to active classroom atmosphere and eliminate students' nervousness is advisable. What teachers should pay attention to is that relaxing classroom atmosphere does not mean disorderliness, and seriousness and tension also are needed for the aim of allowing students to master certain language knowledge and skills. Teachers should adjust atmosphere timely to make it suitable. A good teacher should become the focus of attention of students in the classroom, so that students can feel the teacher's attention and adopt positive attitudes to participate in class learning. To become the focus of the class does not mean that the teacher stand on the platform from beginning to end. In 
group discussions and exercises, teachers can carry on a dialogue with a certain group or student, but in the meanwhile they should pay attention to other students as well as organize some class activities timely to make students stay focused. Teachers' words, expressions, and actions should be appealing enough to arouse students' attention and interests, and their mood and tone should avoid being monotonous or dull.

\section{To Mobilize StUdents’ EnTHUSIASM IN THE Class}

Teaching should be lively in order to mobilize students' enthusiasms. For example, in the primary teaching, when teaching fruits names, teachers can take a basket of fruits to class and tell students the name of each fruit by taking them one by one and guide students to read, then do bilingual translation exercises with students after they can speak the names of various fruits. This not only enables students to have a clear impression of various fruits but contributes to their memories. In the practice and consolidation, teachers can lead students to do fruit squatting game by picking 10 students to play different roles of fruits in the game, then using the doggerel such as "apple squats, apple squats, watermelon squats after apple squats. Watermelon squats, watermelon squats, pineapple squats after watermelon squats" to make it interesting. Through inserting small games like this, students can learn a variety of fruits names quickly in the happiness of playing games. In this way, the dull and boring teaching becomes students' active learning, and they accept new knowledge happily and breesily in these games. Classroom questions also are magical. Questioning is one of the main methods of teaching, the chief means of heuristic teaching, and the key of of conversation. How to question in a proper way, and how to make questions being connected with the real environment have attracted many TCSL teachers to carry out researches. It is crucial that when, where, what and how do teachers guide students and enlight their thinking. It is better for teachers to create the problem situation in class questioning, for example, when saying the word "tourism", teachers can ask students "what do you love to do in holiday?" or "the weather is good this weekend, do you have any plan?". Then teachers should guide students to say the word "tourism" instead of instilling in them directly. This kind of questioning makes students feel that the teacher is chatting with them and it's helpful for students to learn knowledge in a relaxed atmosphere. In the class practice, the teaching method of "cramming" should be avoided, and teachers should talk less to give students more practice time and allow them to express their own meanings without interruption as far as possible. Teachers should keep more "silence" and encourage students to speak, which can make students get relaxed and enhance their self-confidence to lay the root for their next voicing. Practicing in the form of groups is helpful to improve friendship among students as well as playing students' strengths and offer opportunities for them to learn from each other and make progress together.

\section{TO ATTACH IMPORTANCE TO PRAISING STUDENTS}

"Encouragement" plays an important role in teaching. Everyone likes to be praised by others, and students also want to get approval and praise from teachers. Appropriate and timely praise can eliminate students' anxiety and help them to establish confidence. If an introverted student raises his hand for the first time, whether or not the answer is correct, teachers should give him affirmation and praise. In most cases, teachers should give praise to students after they answering questions, even if the responses they offered are wrong, teachers should praise them from other aspects instead, for example, their pronunciation for teachers' praise is very important for students in early stages. Adopting this way, students will have more confidence to offer correct answers, while those who answer wrong will not be excessively self-condemned. TCSL teachers should have a good control of class order and pay attention to skills and methods in maintaining class order. The most common and the least favorite situations by teachers are that students do not listen carefully and students come late and leave early. Some students often play nicknacks in class, not necessarily being a toy; the nicknacks could be anything such as pens, headsets, mobile phones even small pieces of paper and so on. The conditions appear mostly because that most of the students can not concentrate on learning in class and lack interests in Chinese learning, so it is easy to divide attentions by other things. Or owning to that students are in fact absentminded and thinking other things in mind, so they play nicknacks unconsciously. Whenever there is such a situation, it is a warning to teachers: the student is not concentrating on the lecture. At this time, reminding students to pay attention to the class in front of all students may not be appropriate especially when it happens on introverted and sensitive students, teacher's action will hurt their self-esteem. It is best to go to the student slowly and tap his desk as a reminder. If the majority of students are absent-minded, it is likely that the teacher's curriculum content is too boring or difficult, which causes students being tired, the teacher at this time can speak some jokes or stories to active class atmosphere, make students feel at ease and adjust the state of class timely. When the conditions of violating disciplines such as students coming late or leaving early, whispering and being absent-minded in class appear, it is inadvisable that teachers take violent criticism or show extreme emotions immediately, which may destroy the class atmosphere and affect the normal teaching. The measures that giving harsh criticism or kicking the students out are more serious, this will not only damage the students' self-esteem, but dampen the students' enthusiasm for learning. What teachers should do at this time are improving the quality of teaching and developing the relationship between teachers and students to enhance the enthusiasm of students and avoid students' absence and early leaving. Besides, the method of sudden question to attract the scatterbrained students' focus is also advisable.

\section{CONCLUSION}

In short, if the teaching of Chinese as a foreign language is an art, then each class of it is just like a symphony and the teacher is the conductor, responsible for the organization and scheduling of various musical instruments in the whole band to ensure playing a beautiful and harmony music. A class is composed of a variety of elements. Firstly, the element of time: teachers must complete their teaching tasks in a certain period of time. Besides, teachers must make clear the propotion of the composing sectors of reviewing previous knowledges, learning 
new lessons, explaining the knowledge points, giving a summary of this lesson, and setting homework. Secondly, the element of rhythm, teaching in a dull flat style, excessive relaxation and monopoly style should be replaced by flexible and changeful teaching styles full of ups and downs. Thirdly, the element of emotions, teachers should have affinity and should teach through lively activities to mobilize every student's learning enthusiasm. In addition, there are structural elements namely how to begin and end the lesson, and what kind of teaching mode should be adopted to teach new knowledge. More harmonious and reasonable the combination of these elements are, more artistic charm the class teaching effect will have. Teachers should take positive attitudes to control and organize class to promote the harmonious relationship between teachers and students. Whatever situation it is, teachers should firstly find cause from their own, make efforts to improve classroom atmosphere as well as using a variety of teaching techniques to improve their interestingness and the actual case to explain the complicated theory.

\section{REFERENCES}

[1] Wang Junrong. Study on the Teaching Skills of the Teaching of Chinese as A Foreign Language [D]. Sichuan Normal University, 2010

[2] Liu Ying. Analysis on Classroom Management of the Teaching of Chinese as A Foreign Language [J]. Course Education Research: Rearch of the Studying and Teaching Methods, 2016 (3): 24-25.

[3] Li Quan. Theoretical Thinking on Classroom Teaching of Chinese as A Foreign Language [J]. Journal of Renmin University of China, 1996 (05).

[4] Chen Jian. Comprehensive Teaching Method and Class Teaching of Chinese as A Foreign Language [J] Modern Chinese (Language Study Edition), 2008 (09),..

[5] Du Hongyu. Analysis on the Art of Teaching Chinese as A Foreign Language $[\mathrm{J}]$. Journal of Guangxi University (Philosophy and Social Science Edition), 2009

[6] Qi Mingzhu. How to Play the Guiding Role of Teachers in the Teaching of Chinese as A Foreign Language [J]. Youth Literator, 2009 (17) 